\title{
EFL Learners' Behavior States and Academic Outcomes during Playing Games Strategy
}

\author{
Rashed Alghamdy \\ College of Education, Al- Baha University, Saudi Arabia
}

\begin{abstract}
To identify the impact of playing games on the achievements of EFL learners, a quasi-experimental design study was applied for 4 weeks at an elementary school in Saudi Arabia. This study examines the impact of playing games in enhancing EFL students' English skills ability in learning English as a foreign language context. In particular, this study purposes to investigate the impact of playing games in comparison to traditional learning in learning English skills on the achievement of EFL learners and their behavioral states during playing games. The participants in this study were 52 male pupils, aged 12-15 years, level six at an elementary government school in Al-Baha City. According to the results from the post-test obtained they highlight statistical variances between the average scores from the EFL learners who were taught English within the learning method of playing games and the control group taught English using traditional learning methods. The variances favored the experimental group nevertheless the findings in the pre-test score suggested there were no statistical variances amid the EFL learners in the first group and those in the other groups in the achievement of English.

Furthermore, the observation findings indicate that the EFL learners in the experimental conditions displayed more playing together behavior states and less playing individually on-task behavior states, non-playing together behavior, and off-task behavior than their classmates in the control condition.
\end{abstract}

Index Terms - applied linguistics, teaching English as a foreign language, playing games strategy, Saudi Arabia

\section{INTRODUCTION}

Research conducted on the use of games indicates that teaching a particular lesson in a game context appeals to learners and enhances their enthusiasm for that lesson (Cornillie et al, 2013). According to Soyluçiçek (2011), games offer communication, sharing, as well as, relaxing fields; which play a crucial role in the students' education process. Currently, in the US and other countries, games are employed as tools to achieve the K-16 educational objectives. For example, Dance Dance Revolution is considered a physically demanding, interactive and digital COTS game involving a wired dance-floor. Thai, Lowenstein, Ching, and Rejeski (2009) assert that a number of states have adopted this game for their main physical fitness programs. The game requires students to reflect a particular movement in life, whereas the receiver through a wired dance floor or hand-held device, detects their performance accuracy and precision (Ghaemi \& Ebrahimi,2015). The teaching of games has developed into a new technique in this era. Enthusiasts of teaching gamed focus their teaching course on learning computer games, language games or motor activity. Studies exhibit that educators take the advantages of gaming features as well as gameplay to accomplish their learning goals and objectives (Gee, 2007; Federation of the American Scientists, 2006). Games can be employed as instructional tools to convey content, enhance second language practice, as well as teaching strategies, skills, and information literacy. For example, Rankin et al. (2006) and Crookall and Oxford (1990) assert that games encourage language practice.

\section{LITERATURE REVIEW}

Independent studies conducted on 329 teachers regarding the application of gaming strategies were analyzed by Haystead and Marzano (2009). The control group design was $(N=14,287)$ and based on this design, the researchers reported an $18 \%$ measurable increase in the application of interactive games as a particular strategy. Also, $5^{\text {th }}$ graders exhibited a $38 \%$ increase in the vocabulary as a result of playing different review games. Some of the games that were used to teach vocabulary include Quia and Pyramid (both are computer-aided games without a 3-dimensional environment). Pyramid refers to a word guessing game, whereas Quia refers to an online question that has a number of gaming formats including concentration, matching, flashcards, word search, challenge board, Battleship, cloze hangman, pop-ups, ordered lists, jumbled words picture perfect, scavenger hunt and patterns (Sandra,2017).

Clark et al. (2014) performed a meta-analysis on sixty-nine K-16 interactive gaming studies. These studies compared gaming with a particular control group from 2002 to 2012. The outcomes were then published in various peer-reviewed journals. This research should have employed random assignment in the particular form of experimental research. Effect sizes were used, and they recorded a .33 standard deviation favoring the use of digital games over no games to enhance interpersonal learning, cognition as well as intrapersonal learning. The positive result concurred with the other scholar's meta-analysis studies regarding the impact of digital games on learning, as mentioned in their reports. 
According to Griva et al. (2010), games are classified into various categories including physical games, role-playing games, arranging puzzles, sorting or ordering as well as cooperative and competitive ones. Also, the categories can be employed as a game-based learning setting. In such a setting, the students learn the game and teachers help them to practice it. The learners are able to gain skills on the required point without any special attention. According to Donmus, (2010) games have positive effects on students including motivation, enhanced attention, different learning environment, as well as grasping the concept longer.

According to Thai et al. (2009), games offer students intrinsic motivation, as well as, a pathway that will enable learners to achieve autonomy as they navigate through the world. For instance, games teach students self-regulation, behaviors, systems thinking, problem-solving as well as self-concepts (Thai et al., 2009).

\section{PURPOSE OF THE STUDY}

The main purpose of this study is to identify how playing games enhance and provide more interactive and increase the outcomes of EFL students in English and how they behave during playing with each other. In the study the researcher aimed to find a new methodology which may help students to improve their English achievements and eventually facilitate their interactions among their peers. The playing games method might be the solution because the learners have the opportunity to play with their colleagues and communicate with each other to learn different English skills.

\section{METHODS}

\section{A. Research Questions}

1. What is the impact of playing games strategy on the EFL learners' outcomes in learning vocabulary?

2. How do EFL learners behave during playing games strategy?

3. Do EFL learners Play with each other or they play individually?

4. Do EFL learners playing with Competitive behavior or Off-task behavior?

The researcher collected only quantitative data in this study. The instruments that were used to collect data is a pretest and post-test English achievement test and observation timetable.

\section{B. Participants}

The study involved participants fifty-two being male pupils aged between eleven and thirteen years being at level six within a government elementary school in the Al-Baha city. The classes were assigned randomly to one of two conditions. One class was selected randomly to create the experimental group and another class was selected randomly as the control group. There were twenty-seven pupils in the playing games method having experimental conditions and twenty-five pupils in traditional learning method having control conditions. Additionally, two male English educators from the institution were involved as participants in the study. All English educators had relevant qualifications including Bachelor Degrees in English and similar experiences teaching English.

\section{English Achievement Test}

The test offered was utilized as both the post-test and pre-test to look into the effect of the method of playing games on pupil's achievement of the English language especially in grasping vocabulary. The test was comprised of twenty score points. The time given was thirty minutes. At the start of the test the participants were asked to listed and give value to the words. There were colored pictures and numerous words. The students then listed to a stereo while giving matches for the word to the correct picture. Also, songs and moving games were present during the test. One single mark allotted for every correct answer in the exam.

The previous achievements of the participants in English became evaluated using the pre-test given to each conditions before the study started. The pre-test served the purpose of assessing the background vocabulary knowledge of the students. A similar pre-test was given at the climax of the study as a post-test to check the achievements of the participants in the English achievement test. The post-test was purposeful in evaluating the effect of both of the playing games method and the traditional method on student's achievements. One English teacher who was not part of the study corrected the test papers. He marked the test paper both at the start and at the end of the study.

\section{Observation Timetable}

The researchers made videotapes of two classes at a single elementary government school: the first class in the experimental conditions who have obtained training in playing games and the other class within the control conditions who had no such training for a period of four weeks. In the experimental conditions class pupils were in group divisions of four and each division became video-taped triple times for fifteen minutes each. Likewise in the control class the researcher asked the teachers to form group divisions of four in every classroom and each group became video-recorded triple times for fifteen minutes each.

The English teacher of the experimental conditions class was involved in a workshop that built their knowledge of the implementation process of playing games in their classrooms. The other English teacher in the control conditions class did not participate in the training workshop. Nonetheless, the researcher spent the time introducing them to 
various books regarding teaching English as a second language in Saudi Arabia. The learners in both the control and experimental conditions studied similar English lessons in their groups for one hour, four times in a week.

The study concentrated on several behavior states in each video clip including;

1-Playing together behavior (playing with his classmates)

2-Non-playing together behavior (competitive behavior)

3-Individual on-task behavior (playing individually)

4-Off-task behavior (Not playing with his friends and not playing individually)

\section{E. Procedures}

The study developed two separate workshops; one for the experimental group teacher who received training in playing games method learning skills and the other for a teacher within a traditional class setting where learners operated in traditional method but failed to obtaining training in methods of implementing playing games learning.

The study was done from the start of the first semester in 2018 for three weeks. In the beginning the researcher invited from Al-Baha school two English teachers to be part of the research. Two classes from elementary school were asked to participate in the research. One class was assigned the experimental group status and the other control group status. A ministry of education assigned textbook was used as the teaching material for both the control and experimental groups.

The students took part in different games such as listening to songs then repeating them, coloring various pictures, acting various roles, hide and seek, moving games and so forth. The teacher in the experimental group class and the one in the control group class taught one class each. They each taught similar content to all classes for a three weeks period. The English achievement test served as both a pre-test and post-test to look into the effect of the learning method of playing games on EFL learners. At the start of the test the participants were tasked to select the correct answers from the options and the time given for the test was thirty minutes.

The previous achievements of the participants in learning English became evaluated using the pre-test given to both experimental and control conditions before beginning the study. The pre-test served the purpose of assessing the background knowledge of student's in general English skills. The tests reliability is high having an Alpha-Cronbach of eighty-three. A similar pre-test was available at the climax of the study as a post-test to check the achievements of participants on the listening and vocabulary skills. The purpose of the post-test remained to be the assessment of the influence of both the playing games method and traditional learning on achievement of students.

\section{RESUlTS AND DisCUSSIONS}

\section{A. Findings of the Achievement Test}

Fifty-two participants were involved in the study having been obtained evenly from two classes from a government elementary school who experienced either the control condition or the experimental condition. To figure out if variances existed in the EFL students' scores in the English skills in both the conditions, an analysis of variance was done. The standard deviation and means of the English achievement pre-test and pre-test score are highlighted in Table 1 .

TABLE I.

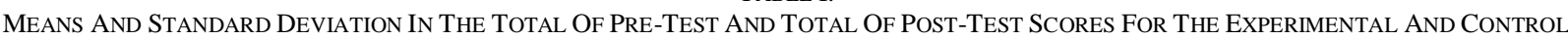
CONDITIONS.

\begin{tabular}{ccccc}
\hline \hline & & $\mathrm{N}$ & $\mathrm{M}$ & $\mathrm{SD}$ \\
\hline & control & 25 & 11.04 & 2.720 \\
& experimental & 27 & 11.15 & 2.365 \\
Pre-test total scores & Total & & 11.09 & 2.521 \\
& & 52 & & \\
& & & 12.54 & 2.549 \\
& control & 25 & 15.33 & 1.901 \\
Post-test total scores & experimental & 27 & 13.96 & 2.631 \\
& Total & 52 & & \\
\hline \hline
\end{tabular}

In order to determine if there were differences between both the pre-test and post-test total score results, one-way ANOVAs were conducted. As can be seen in Table 2, there were no significant differences between the experimental and control conditions at Time 1 but there were significant differences at Time 2 (Alghamdi \& Gillies, 2013). 
TABLE II.

Tests Of Between-Subject EFFects For PRE-Test And Post-Test Total SCORES

\begin{tabular}{llrrrrr}
\hline ANOVA & & SS & df & MS & F & Sig. \\
\hline Pre-test total scores & Between Groups & .159 & 1 & .159 & .025 & .876 \\
& Within Groups & 330.369 & 51 & 6.478 & & \\
& Total & 330.528 & 52 & & & \\
Post-test total scores & Between Groups & 103.463 & 1 & 103.463 & 20.575 & .000 \\
& Within Groups & 256.462 & 51 & 5.029 & & \\
& Total & 359.925 & 52 & & & \\
\hline
\end{tabular}

\section{Discussion}

Table 1 indicates that statistical variances do not exist, $p=0.876(p>0.05)$, between the average results of the EFL students who became taught English in the playing games method and the ones who were taught English utilizing the traditional method in the pre-test (Alghamdi \& Gillies, 2013).

Table 2 highlights that significant statistical variances exist, $p=0.000(p<0.05)$ between the average score of the EFL students who became taught in the playing games method of learning and those taught English with the traditional method in that post-test with preference on the experimental conditions.

The findings indicated that there are statistically significant differences, $p=0.000(p<0.05)$ between the mean scores of the EFL learners who were taught English through playing games environment (the experimental group), and those who were taught the English by using the traditional learning method (the control group) in the post-test. This difference was in favor of the experimental group. However, the findings highlighted that there are no statistically significant differences between the learners in the experimental classes and the others in the control conditions in their English achievement test score at the pre-test.

These findings highlight the fact that the students had the same background knowledge of the items before the implementing of playing games strategy, confirming that any gain in the EFL learners' achievements could be attributed to the playing games strategy. This research found that playing games strategy has a strong effect on EFL learners' outcomes. The result is in line with other findings like Turgut and Irgin (2009) which highlighted the efficiency of playing games on the young learners' language learning. Another study has done by Soyluçiçek (2011) showed that games offer positive communications among students, sharing different roles, which play a crucial role in the students' learning another language skill. Rankin et al. (2006) and Crookall and Oxford (1990) found that playing games strategy encourage acquiring language skills.

\section{B. Findings of Observational Data}

A test known as Kruskal-Wallis was utilized to determine the whole impact of the intervention on the behavior states of the learners in the two conditions in the total three period of time. The specific test is used when datasets are small and allows for between groups effects to be recognized. Since each class was video-recorded three times in the entire study either in the control or experimental conditions the researcher evaluated and deliberated over all the video clips starting from time one to three in order to provide better and reliable results. The eights classes had been video-taped at the first week, the middle being second and third week and final stage of the study being week four.

\section{Learners behavior states (Time one, weeks one to two)}

To determine existing differences in the learners states of behavior between the conditions at time one, KruskalWallis test were done on the incidence of recorded states of behavior for the students in either experimental or control conditions.

TABLE III.

TESTS OF BETWEEN-GROUP EFFECTS FOR FOUR BEHAVIOUR VARIABLES AT TIME 1 BY CONDITION

\begin{tabular}{|c|c|c|c|c|}
\hline Variables & $\mathrm{N}$ & Mdn & $X^{2}$ & $P$ \\
\hline \multicolumn{5}{|c|}{ Play together behavior } \\
\hline Control & 16 & 8.00 & \multirow{2}{*}{34.179} & \multirow{2}{*}{.000} \\
\hline Experimental & 16 & 11.50 & & \\
\hline \multicolumn{5}{|c|}{ Non-playing together behavior } \\
\hline Control & 16 & 2.50 & \multirow{2}{*}{8.940} & \multirow{2}{*}{.003} \\
\hline Experimental & 16 & 1.00 & & \\
\hline \multicolumn{5}{|c|}{ Playing Individually } \\
\hline Control & 16 & 3.00 & \multirow{2}{*}{19.689} & \multirow{2}{*}{.000} \\
\hline Experimental & 16 & 1.00 & & \\
\hline \multicolumn{5}{|c|}{ Off-Task Behavior } \\
\hline Control & 16 & 2.50 & \multirow{2}{*}{8.753} & \multirow{2}{*}{.003} \\
\hline Experimental & 16 & 1.00 & & \\
\hline
\end{tabular}

2. Discussions

Table three shows significant variances between the conditions within play together behavior, $X^{2}(2, N=16)=$ $34.179, p=.000$; non-play together behavior, $X^{2}\left(2, N=16=8.940, p=.000\right.$; individually behavior, $X^{2}(2, N=16)=$ 
19.689, $p=.000$; individual off-task behavior, $X^{2}(2, N=16)=8.753, p=.003$ (Alghamdi, 2018).

The results indicated that the learners in the experimental conditions play more together compared to those in the control conditions $(\mathrm{Mdn}=11.5, N=16)$ at time one. In addition, the results indicated the importance between the learners within the experimental condition and the learners in the control conditions in terms of behavior $(\mathrm{Mdn}=1, N=$ 16).

An examination of the Kruskal-Wallis tests indicated that the students in the experimental conditions showed more playing together behavioral states and less non-playing together behavior states, playing individually and individual nontask behaviors than their classmates in the control condition.

In addition, outcome scores were, on average, higher in the experimental condition for playing together behavioral outcomes. They were lower in the experimental condition for Non-playing together behavior, playing individually and individual nontask behaviors.

\section{Students' Behavior States (Time 2, Weeks 3 to 4)}

Similarly, in order to determine if there were differences in the students' behavior states between the conditions at Time 2, four Kruskal-Wallis tests were conducted on the frequency of recorded behavior states for the students in the different conditions.

TABLE IV.

TESTS OF BETWEEN-GROUP EFFECTS FOR FOUR BEHAVIOUR VARIABLES AT TIME 2 BY CONDITION

\begin{tabular}{|c|c|c|c|c|}
\hline Variables & $N$ & Mdn & $X^{2}$ & $P$ \\
\hline $\begin{array}{l}\text { Play together behavior } \\
\text { Control } \\
\text { Experimental }\end{array}$ & $\begin{array}{l}16 \\
16 \\
\end{array}$ & $\begin{array}{l}7.00 \\
13.00 \\
\end{array}$ & 38.801 & .000 \\
\hline $\begin{array}{l}\text { Non-playing together behavior } \\
\text { Control } \\
\text { Experimental }\end{array}$ & $\begin{array}{l}16 \\
16 \\
\end{array}$ & $\begin{array}{l}3.00 \\
1.00 \\
\end{array}$ & 24.577 & .000 \\
\hline $\begin{array}{l}\text { playing individually } \\
\text { Control } \\
\text { Experimental }\end{array}$ & $\begin{array}{l}16 \\
16 \\
\end{array}$ & $\begin{array}{l}2.00 \\
1.50 \\
\end{array}$ & 30.382 & .000 \\
\hline $\begin{array}{l}\text { Off-task behavior } \\
\text { Control } \\
\text { Experimental }\end{array}$ & $\begin{array}{l}16 \\
16\end{array}$ & $\begin{array}{l}2.00 \\
1.00\end{array}$ & 18.155 & .000 \\
\hline
\end{tabular}

\section{Discussion}

It is evident from Table 4 above that there were significant differences between the conditions in: play together behavior, $X^{2}(2, N=16)=38.801, p=.000$; non-play together behavior, $X^{2}(2, N=16=24.577, p=.000$; playing individually behavior, $X^{2}(2, N=16)=30.382, p=.000$; ; individual off-task behavior, $X^{2}(2, N=16)=18.155, p=.000$.

The results showed that the students in the experimental condition play together more than their peers in the control condition $(\mathrm{Mdn}=13.00, N=16)$ at Time 1 . Moreover, the results pointed out the significance between the students in the experimental condition and the students' in the control condition in terms of -task behavior $(\mathrm{Mdn}=1, N=16)$.

An examination of the Kruskal-Wallis tests indicated that the students in the experimental conditions showed more playing together behavioral states and less non-playing together behavior states, playing individually and individual nontask behaviors than their classmates in the control condition.

In addition, outcome scores were, on average, higher in the experimental condition for playing together behavioral outcomes. They were lower in the experimental condition for Non-playing together behavior, playing individually and individual nontask behaviors

The purpose of this research was to investigate if there were differences in the behaviors of the EFL learners in the playing games groups and traditional learning groups. In order to examine the differences in the behavior states of EFL learners, the present study also looked at whether the students' achievements in English are positive or not and evaluated the extent to which their behavior states affect their achievement in a playing games environment. The findings, as stated above, have indicated that the learners achieved more scores in the playing games condition than did their peers in the traditional learning condition (Alghamdi, 2018).

Thai et al. (2009), highlighted that games teach students self-regulation, behaviors states, systems thinking, problemsolving as well as self-concepts. Griva et al. (2010) indicated that games are classified into different categories such as physical games, role-play games and cooperative and competitive ones. According to Donmus, (2010) playing games have strong positive effects on learners such as motivation, different learning environment. Thai, Lowenstein, Ching, and Rejeski (2009) confirmed that a number of states have adopted playing games for their main physical fitness programs.

\section{CONCLUSION}

In order to investigate the effect of the playing games method of learning on the success of EFL learners, a design study known as quasi-experimental became applied for four weeks at a government elementary school. The study looks 
into the influence of playing games in improving ability of English skills of EFL learners in acquiring English as an alien language. In essence, the study aims to evaluate the influence of the playing games method compared to traditional method of learning in obtaining skills in English on EFL students and their states of behavior during playing games method. The findings indicated that significant statistical variances exist in that post-test when comparing the average scores of the EFL students who learnt English skills using the playing games method of learning and those who became taught English using traditional method of learning thus favoring the group under experimental strategy environment. Moreover, the observational findings show that the EFL students in the experimental conditions indicated more playing together behaviors and reduced playing individually on-task states of behavior, non-playing together states and off-task stages of behavior compared to their classmates within the control conditions

\section{REFERENCES}

[1] Clark, D., Tanner-Smith, E., Killingsworth, S. (2014), Digital Games, Design and Learning: A Systematic Review and MetaAeta-Analysis (Executive Summary). Menlo Park, CA:SRI International

[2] Cornillie, Frederik, Geraldine Clarebout \& Piet Desmet. (2013), The role of feedback in foreign language learning through digital role playing games. Procedia- Social and Behavioral Sciences, 34, 49-5.

[3] Crookall, D., \& Oxford, R. (1990). Language learning through simulation and gaming. New York, NY: Harper \& Row.

[4] Donmus, Vildan. (2010).The use of social networks in educational computer-game based foreign language learning. Procedia Social and Behavioral Sciences. 9, 1497-1503.

[5] Farid Ghaemi and Fateme Ebrahimi. (2015). The Impact of Implementing Computer Games and Motor Activity on Early EFL Vocabulary Achievement. Theory and Practice in Language Studies, Vol. 5, No. 6. Pp. 1216-1225, June 2015 Dol: http://dx.doi.org/10.17507/tpls.0506.14.

[6] Federation of American Scientists. (2005, October). Harnessing the power of video games for learning. FAS Summit of Educational Games. Washington, DC.

[7] Gee. J.p. (2007). What video games have to teach us about learning and literacy (2 ${ }^{\text {nd }}$ ed). New York, NY: Palgrave Macmillan.

[8] Griva, Elni, KlioSemogloua,\&Athina Geladaria. (2010). Early foreign language learning: Implementation overprotecting game-based context. Procedia Social and Behavioral Sciences 2, 3700-3705.

[9] Haystead, M. W., \& marzano, R.J. (2009), Meta-Analytic synthesis of studies conducted at marzano Research Laboratory on instructional strategies. Englewood. CO: Marzano Research Laboratory.

[10] Alghamdi, R. (2018). EFL Learners' Behaviour States During Cooperative Learning Strategy. International Journal of Linguistics. Vol. 10, No. 6.

[11] Aghamdi, R., \& Gillies.R. (2013). The Impact of Cooperative Learning in Comparison to Traditional Learning (Small Groups) on EFL Learners' Outcomes When Learning English as a Foreign Language. Asian Social Science, 9 (13).

[12] Sandra Annette rogers. (2017). A Massively Multiplayer Online Role-playing Game with Language Learning Strategic Activities to Improve English Grammar, Listening, Reading, and Vocabulary. PhD thesis Submitted to the Graduate Faculty of the University of South Alabam.

[13] Soylucicek, Seza. (2011). Graphic design issues on educational computer games for children, Procedia Social and Behavioral Sciences, $\quad 15, \quad 642-645, \quad$ Retrieved September $21, \quad 2012, \quad$ from http://www.sciencedirect.com/science/article/pii/S1877042812015613/pdf?md5=b504777d17810e0ea00e86aeca5e9456\&pid=1 -s2.0-S1877042812015613-main.pdf.

[14] Thai, A. M., Lowenstein, D., Ching, D., Rejeski, Do. (2009). Game changer: Investing in children's play to advance children's learning and health. New York. NY.

Rashed Zannan Alghamdy, is an Assistant professor at Al-Baha University in Education college, Saudi Arabia. His research focuses on Applied Linguistic, Teaching English as Foreign Language, Mobile language learning, Verbal Interaction, discourse analysis, learning process. 